NASA Technical Memorandum 4799

\title{
Dynamic Ground Effect for a Cranked Arrow Wing Airplane
}

Robert E. Curry

Dryden Flight Research Center

Edwards, California

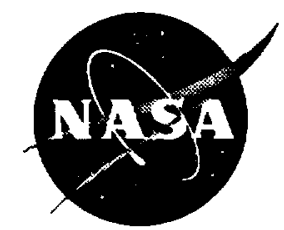

National Aeronautics and

Space Administration

Office of Management

Scientific and Technical Information Program 



\title{
DYNAMIC GROUND EFFECT FOR A CRANKED ARROW WING AIRPLANE
}

\author{
Robert E. Curry* \\ NASA Dryden Flight Research Center \\ Edwards, California
}

\begin{abstract}
$C_{D}$

drag coefficient

Flight-determined ground effect characteristics for an F-16XI airplane are presented and correlated with wind tunnel predictions and similar flight results from other aircraft. Maneuvers were conducted at a variety of flightpath angles. Conventional ground effect fight test methods were used, with the exception that space positioning data were obtained using the differential global positioning system (DGPS). Accuracy of the DGPS was similar to that of optical tracking methods, but it was operationally more attractive. The dynamic flight-determined lift and drag coefficient increments were measurably lower than steady-state wind-tunnel predictions. This relationship is consistent with the results of other aircraft for which similar data are available. Trends in the flight measured lift increments caused by ground effect as a function of flightpath angle were evident but weakly correlated. An engineering model of dynamic ground effect was developed based on linear aerodynamic theory and super-positioning of flows. This model was applied to the F-16XI data set and to previously published data for an F-15 airplane. In both cases, the model provided an engineering estimate of the ratio between the steady-state and dynamic data sets.

$\begin{array}{ll} & \text { Nomenclature } \\ a_{X} & \begin{array}{l}\text { acceleration in } X \text { body axis, } g \text { 's, positive } \\ \text { forward }\end{array} \\ a_{Z} & \begin{array}{l}\text { acceleration in } Z \text { body axis, } g \text { 's, positive } \\ \text { down }\end{array} \\ b & \text { span, } \mathrm{ft} \\ \text { c.g. } & \text { center of gravity }\end{array}$

\footnotetext{
* Chief, Aerodynamics Branch. Member ALAA.

Copyright 11997 by the American Institute of Aeronautics and
} Astronautics, Inc. No copyright is asserted in the United States under Title 17, U.S. Code. The U.S. Government has a royalty-free license to exercise all rights under the copyright claimed herein for Governmental purposes. All other rights are reserved by the copyright owner.




$$
\begin{array}{ll}
\Delta C_{m_{g e}} & \begin{array}{r}
\text { incremental change in pitching moment } \\
\text { coefficient due to ground effect about } \\
\text { the reference c.g. (FS 324) }
\end{array} \\
\varepsilon & \begin{array}{l}
\text { effective wake angle, deg } \\
\theta
\end{array} \\
\text { pitch attitude, deg }
\end{array}
$$

\section{Subscripts}

$\begin{array}{ll}\begin{array}{l}\text { dynamic } \\ \text { image }\end{array} & \begin{array}{c}\text { varying height above ground (non-zero } \\ \text { flightpath angle) } \\ \text { refers to imaged airplane }\end{array} \\ \text { steady-state } & \begin{array}{l}\text { constant height above ground } \\ \text { uncorrected }\end{array} \\ \begin{array}{l}\text { uncorrected for variations in angle-of- } \\ \text { attack or elevon position }\end{array} \\ \alpha & \begin{array}{c}\text { partial derivative with respect to angle of } \\ \text { attack }\end{array} \\ \delta \mathrm{e} & \begin{array}{c}\text { partial derivative with respect to elevon } \\ \text { position }\end{array}\end{array}$

\section{Introduction}

Proximity to the ground can produce significant effect on the aerodynamic characteristics of any aircraft. The primary effect tends to be an increase in lift coefficient with changes in the drag and pitching moment of similar magnitude. A nosedown pitching moment generally occurs, and the change in drag coefficient may be positive or negative. The ground effect on airdata measurements may be subtle but have significant effects on flying characteristics, particularly if they are used as an input to the flight control system. The ground effect on stability and control derivatives are generally of less importance, except perhaps for vehicles which operate continuously close to the ground. In most cases, ground effects are not particularly adverse and are easily compensated for by piloting technique. However, improved understanding of the phenomenon could allow increased confidence and detail in the prediction of flying qualities that would contribute to development of more sophisticated landing systems or development of autonomous vehicles.

Ground effect was originally studied as a steady-state situation in which incremental changes to aerodynamic forces and moments were determined as a function of height above ground. Conventional wind tunnels have been used to predict steady-state ground effects, and results have been successfully correlated with steadystate analytical methods. ${ }^{1}$ During a series of flight tests of low-aspect ratio aircraft beginning in the late 1960's, however, a distinct difference between data obtained from steady-state wind-tunnel testing (constant height above ground) and dynamic flight data (descending to the ground) was documented. ${ }^{2}$ This distinction was verified through subsequent wind-tunnel experiments in which the dynamic conditions of descending flight were simulated..$^{3-9}$ Recent flight testing, ${ }^{10,11}$ has confirmed the distinction between steady-state and dynamic data and has identified trends which depend on sink rate. Although clearly documented, a satisfactory physical explanation for the dynamic effects has not been proven. This limitation is largely because of the difficulty inherent in obtaining adequate experimental data in a dynamic situation.

The wind-tunnel data in references 3-5 were obtained while moving the sting-mounted model vertically toward the ground plane. The data from references 6-9 were obtained by moving a model horizontally through a static test chamber toward an inclined plane. Despite these innovative testing concepts, their application has been limited to low-speed tunnels with lightweight, simple models. In both cases, the extraction of aerodynamic ground effect was complicated due to the relatively large inertial loads from the dynamic motion of the sting and balance. Data from references 3-5 were limited to constant rates of descent (or sink rate) for a given run, and data from references 6-9 were limited to a constant glidepath angle. During typical landings, both sink rate and glidepath angle vary continuously during the portion of flight influenced by ground effect.

Although flight testing can obtain data in a more realistic dynamic scenario, the measurement process is still challenging. A fundamental limitation is that the airplane must be operated within a small range of vertical and horizontal velocities whenever it is in close proximity to the ground to ensure flight safety. As the airplane approaches the ground and its flightpath flares, many parameters (angle of attack, dynamic pressure, control surface positions) tend to vary systematically, which complicates the extraction of pure aerodynamic ground effects. These difficulties associated with experimentation added to the generally benign nature of ground effects for conventional aircraft have limited the study of the dynamic ground effect problem.

Because ground effects tend to be more significant for low-aspect ratio aircraft, the phenomenon has received considerable attention in the development of supersonic transport aircraft which use slender wing configurations. $^{12}$ The sensitivity of low-aspect-ratio aircraft to ground effect was part of the motivation for 
studies in the 1960's and 70's. The current high-speed civil transport, ${ }^{13}$ has again motivated research into this field. The increased reliance on flight simulation during aircraft design and the desire for increasingly sophisticated flight control modes in the landing and takeoff phase also justify an increased effort in this area. A particular contribution to the field would be a physical explanation of the dynamic effects.

The primary objective of the current effort is to obtain a set of ground effect data with suitable detail and accuracy to study the dynamic nature of the problem. A second objective is to propose an engineering model of the dynamic problem and evaluate an algorithm based on this model using flight data.

Flight testing was conducted using an F-16XL airplane with a low-aspect-ratio (1.75), cranked arrow wing similar to configurations proposed for the High Speed Civil Transport program. The flight test approach and data analysis methods were similar to previous programs with the exception of a differential global positioning system (DGPS) that was used to obtain space position information.

This paper describes the flight testing with an assessment of accuracies, particularly with regard to use of the DGPS. The flight-measured increments in lift, drag, and pitching moment are presented and compared with steady-state wind tunnel data. The relationship between static and dynamic data are compared with that of other configurations for which similar data are available. Then, the lift data are examined for specific trends with respect to flightpath angle. Lastly, proposed engineering model of dynamic ground effect is developed and applied to the data from this study and to data from one other configuration. Use of trade names or names of manufacturers in this document does not constitute an official endorsement of such products or manufacturers, either expressed or implied, by the National Aeronautics and Space Administration.

\section{Vehicle Description}

The F-16XI ship 1 is a high-performance, single-seat airplane with a cranked arrow wing designed for supersonic cruise flight. The configuration layout and a photograph of the vehicle are shown in figure 1. Some key physical properties are summarized in Table 1. A general description of the airplane can be found in references 14 and 15. During this flight test experiment, the airplane was configured with a research airdata noseboom and a dummy Sidewinder missile on each wingtip.

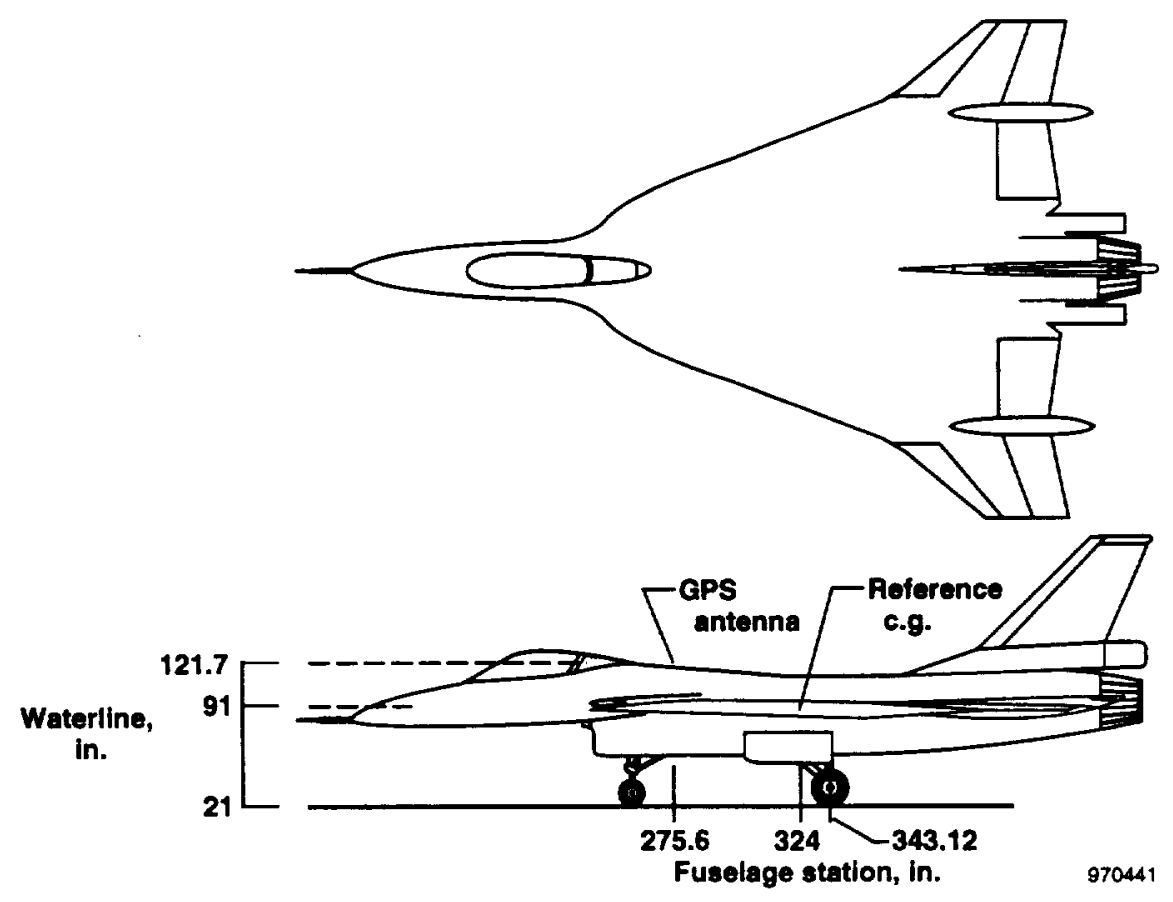

(a) General arrangement.

Figure 1. F-16XL research aircraft. 


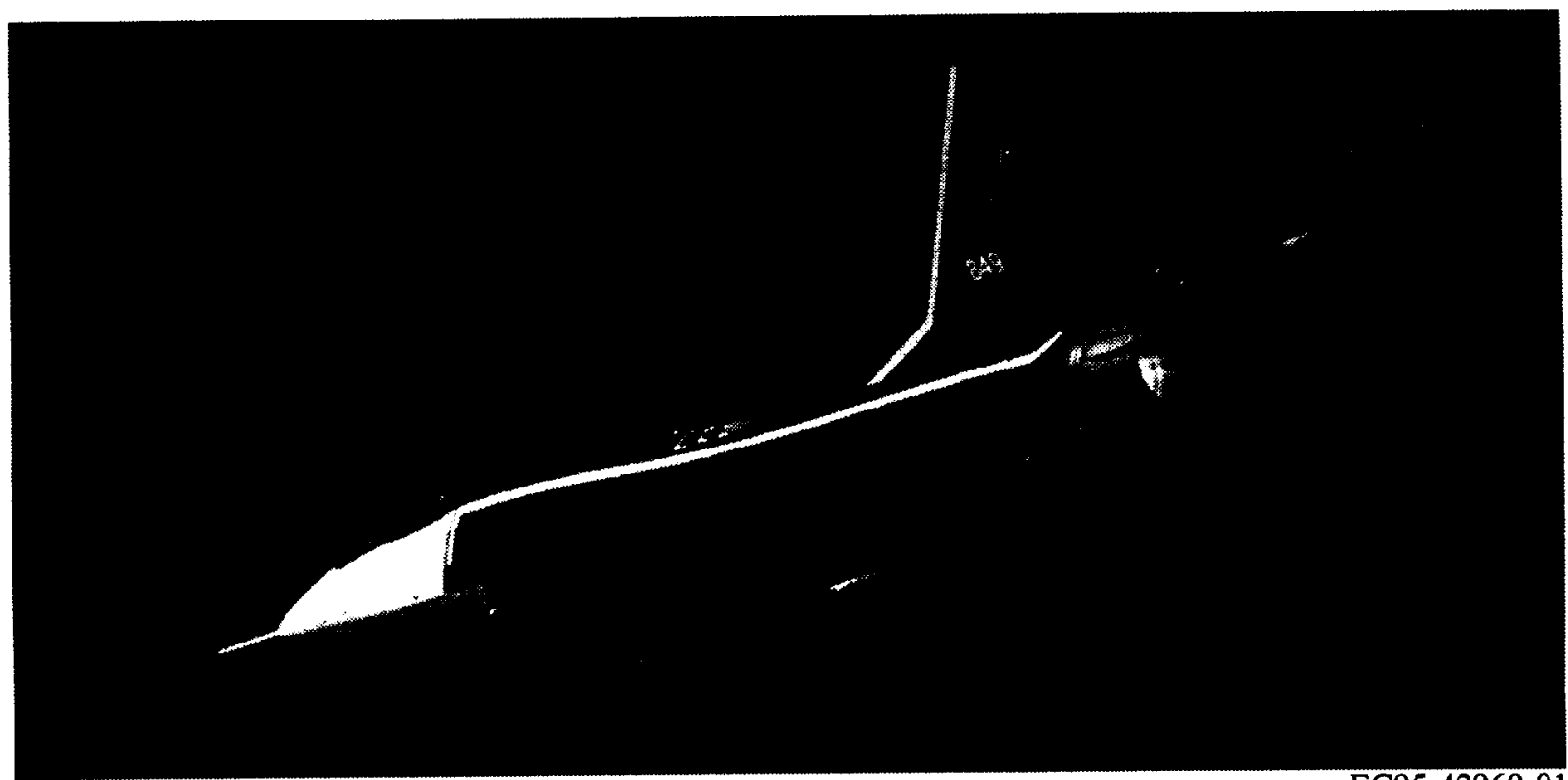

EC95-42960-01

(b) In flight.

Figure 1. Concluded.

Table 1. Physical properties of F-16XL ship 1.

\begin{tabular}{lc}
\hline \hline Reference area, $\mathrm{ft}^{2}$ & 600 \\
Reference chord, in. & 296.4 \\
Reference span, $\mathrm{ft}$ & 32.4 \\
Reference center of gravity & FS 324 \\
Inboard sweep, deg & 70 \\
Outboard sweep, deg & 50 \\
Aspect ratio & 1.75 \\
Length overall, ft & 54.155 \\
Operating weight (zero fuel), lb & 23,947 \\
Typical weight during test maneuvers, lb & 26,500 \\
\hline
\end{tabular}

The airplane has inboard and outboard trailing-edge control surfaces and an outboard leading-edge flap. In the low-speed flight regime of this experiment, the outboard leading-edge flap was not deflected and pitch control was achieved by moving the trailing-edge surfaces essentially in unison. Elevon position, $\delta e$, was defined as the average position of the two inboard surfaces.

\section{Flight Testing}

\section{Measurements}

Data for this experiment were obtained from the global positioning system (GPS), a variety of onboard sensors, and ground-based wind speed and direction sensors located near the runway.

The airplane was equipped with a GPS antenna (fig. 1) and an Ashtech Z-12 unit (Ashtech, Sunnyvale, California) ${ }^{16}$ which stored GPS data in internal memory at a rate of 1-sample-per-second (sps). After each flight, these data were downloaded into a personal computer and merged with data from a GPS ground station using the Ashtech Precise Differential GPS Navigation and Surveying, $\left(\mathrm{PNAV}^{\mathrm{TM}}\right)$, software. ${ }^{16}$ This software computes time and space position data and then derives other useful parameters such as flightpath angle and ground speed. The PNAV software also determines several indications of the fidelity of the solution based on the quality of the satellite data available. In particular, PNAV estimates the root mean square uncertainty in the space position data. During the majority of the flight testing, PNAV indicated space position root mean square uncertainties of 0.15 to $0.3 \mathrm{ft}$. Maneuvers in which the root mean square exceeded $0.3 \mathrm{ft}$ were discarded from further analysis.

The same type of DGPS equipment was set up at various positions on the test runway to obtain precise information about the geometric location of the runway. These data were used to develop an analytical model of the runway surface which was combined with the flight

\footnotetext{
${ }^{\text {IM }}$ PNAV is a registered trademark of Ashtech, Incorporated, Sunnyvale, California
} 
data to obtain the relative height of the GPS antenna of the airplane to the local runway surface. The pitch attitude of the airplane was then used to compute the height of the aerodynamic center of the wing.

During many maneuvers, the airplane main gear touched down on the runway, and these events were used as an independent check on the accuracy of the DGPS measurements. Whenever the airplane contacted the runway and the DGPS diagnostics indicated a valid solution (root mean square less than $0.3 \mathrm{ft}$ ), the DGPS measurement was $\pm 1 \mathrm{ft}$ of the expected value. This variation was considered acceptable for the experiment and is equivalent to the accuracy of optical systems which have been used for previous ground effect testing. As a result, the PNAV diagnostics were felt to be a reliable indication of the quality of the space position data for all maneuvers, even when they did not include touchdown on the runway.

The most significant advantage of the DGPS for this application is that it was available whenever the aircraft was in flight. Use of ground-based optical systems requires preflight planning and a labor-intensive postflight analysis. With the DGPS, the airplane could divert from other flight objectives to conduct ground effect maneuvers whenever conditions were appropriate without prior coordination with ground-based tracking services.

Data from an extensive onboard research instrumentation system were acquired and encoded using a 12-bit pulse code modulation system and telemetered to a ground station. Sensors included inertial parameters, control surface positions, power lever angle, engine core rotational speeds, fuel quantities, and freestream airdata. The inertial sensors which included linear accelerations, attitudes, and angular rates oriented in the three body axes were located within 1 in. of the airplane reference longitudinal center of gravity (c.g.) (FS 324); therefore, no corrections for sensor location were made. The majority of sensors used for this study were sampled at a rate of 50 sps.

The airplane was equipped with an airdata noseboom, configured with total and static pressure transducers as well as flow direction vanes for angles of attack and angles of sideslip measurements. Because these sensors respond to aerodynamic flow, however, they are susceptible to errors induced by aerodynamic ground effect and must be used with caution during ground effect flight testing. Both angle of attack and altitude were derived from nonaerodynamic data sources to identify ground effects on the noseboom airdata measurements.
As previously described, data from the DGPS was used to determine geometric altitude, and this information was used to identify variations in the pressure altitude measured at the noseboom. Ground effects on this noseboom measurement produced an error of approximately $25 \mathrm{ft}$ when the airplane is on the ground. This error is consistent with the ground effect error determined on other noseboom configured aircraft. ${ }^{10}$ Although insignificant for most flight operations, this error would be unacceptable as an altitude measurement for ground effect flight testing. Therefore, for this experiment, ground effects are shown as a function of geometric altitude determined from the DGPS.

The magnitude of ground effect-induced error on the noseboom measurement of angle of attack was also examined. The pitch attitude and DGPS-measured flightpath angle were combined to provide a nonaerodynamic measurement of angle of attack. Comparisons of the nonaerodynamic measurement and the noseboom vane did not reveal a significant error due to ground effect. Because of the better resolution of the noseboom vane and inconsistencies in the pitch attitude measurement, the primary measurement of angle of attack for this experiment was the noseboom vane. A resonant frequency at $9.25 \mathrm{~Hz}$ was noted in the angle-ofattack vane data, and a digital notch filter was used to minimize this affect in the data.

\section{Elight Test Techniques}

Twenty-four maneuvers were conducted over the course of seven flights. Before each maneuver, the pilot extended the landing gear, aligned the airplane with the runway, and began a descent at a predetermined glide slope and angle of attack. After stabilizing on the desired flight conditions, the pilot attempted to hold the power constant and make minimal control surface inputs. As the airplane approached the runway and responded to ground effect, the pilot continued to hold the throttle constant and attempted to maintain a constant angle of attack using longitudinal stick inputs. The maneuver was complete when the airplane touched down or the pilot adjusted the throttle. The time history for a typical maneuver (fig. 2) shows some of the maneuver set-up (in which engine thrust level is still being adjusted) and the data analysis time segment.

The development of this maneuver, termed a "constant-alpha-approach," is described in reference 17. The use of constant throttle setting and nearly constant angle of attack eliminates the source of many potential errors in the data analysis, as will be shown. 

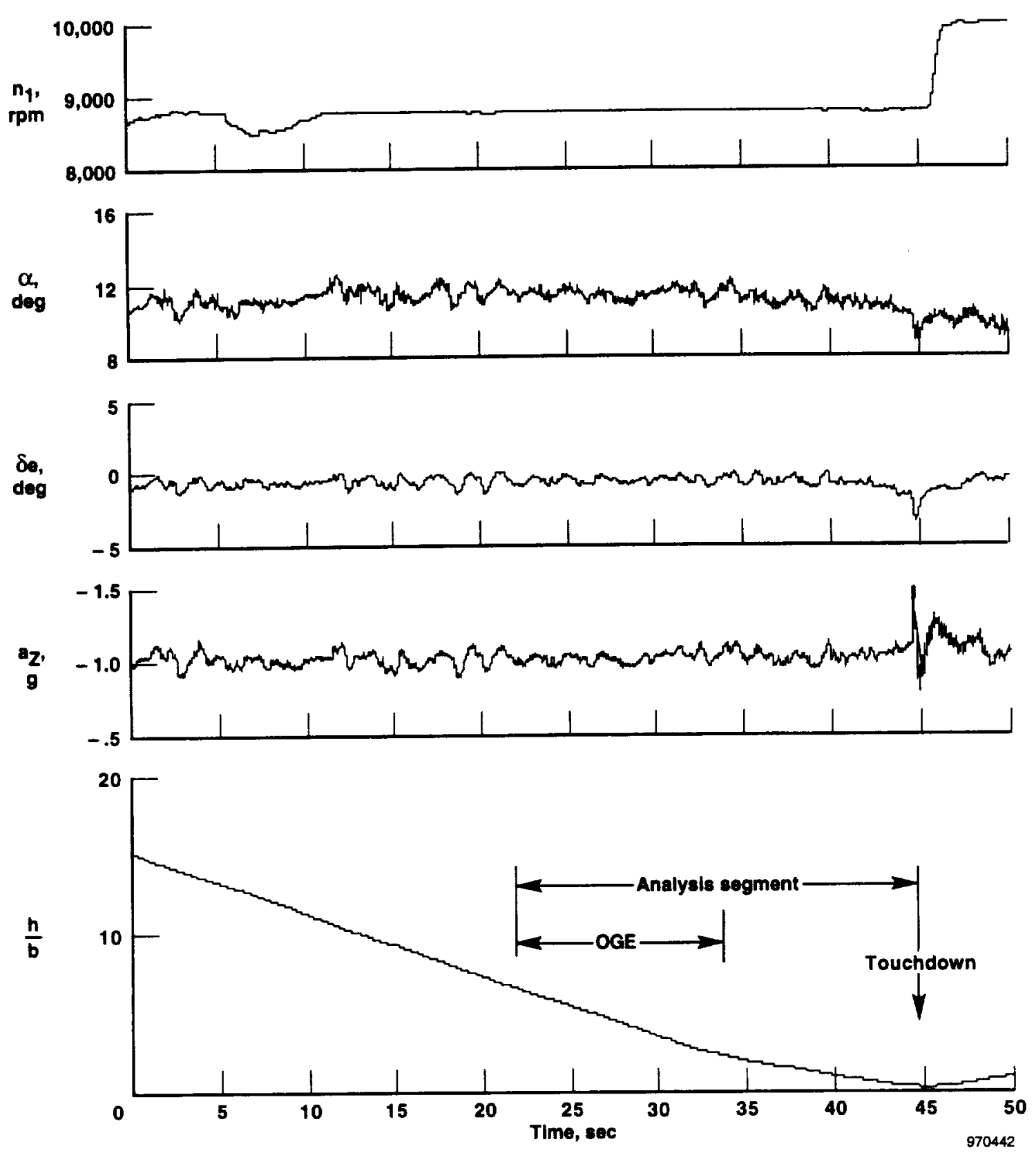

Figure 2. Time history of typical ground effect flight test maneuver (flight 138, maneuver 2).

An attempt was made to conduct maneuvers at a range of glide slope angles. The pilot used the Instrument Landing System (IIS) glide slope indicator as an aid in setting up the initial condition. Figure 3 shows the flightpath angle as a function of height above ground for a typical constant-angle-of-attack maneuver. The flightpath angle is fairly constant during the descent to a height of about one span; however, it begins to roundout or flare naturally as the airplane responds to the resulting increase in lift because of ground effect. On some maneuvers, the airplane flared to level flight before touching down.

The range of flightpath angles that could be evaluated was limited by the obvious requirement to touchdown within acceptable vertical and horizontal speed limits. The envelope of fightpath angles used in this study (fig. 3) ranges from $-1^{\circ}$ to $-3^{\circ}$ at altitudes above ground effect. However, this envelope decreases to a range of $0^{\circ}$ to $-1.9^{\circ}$ at a height of one-half span. 


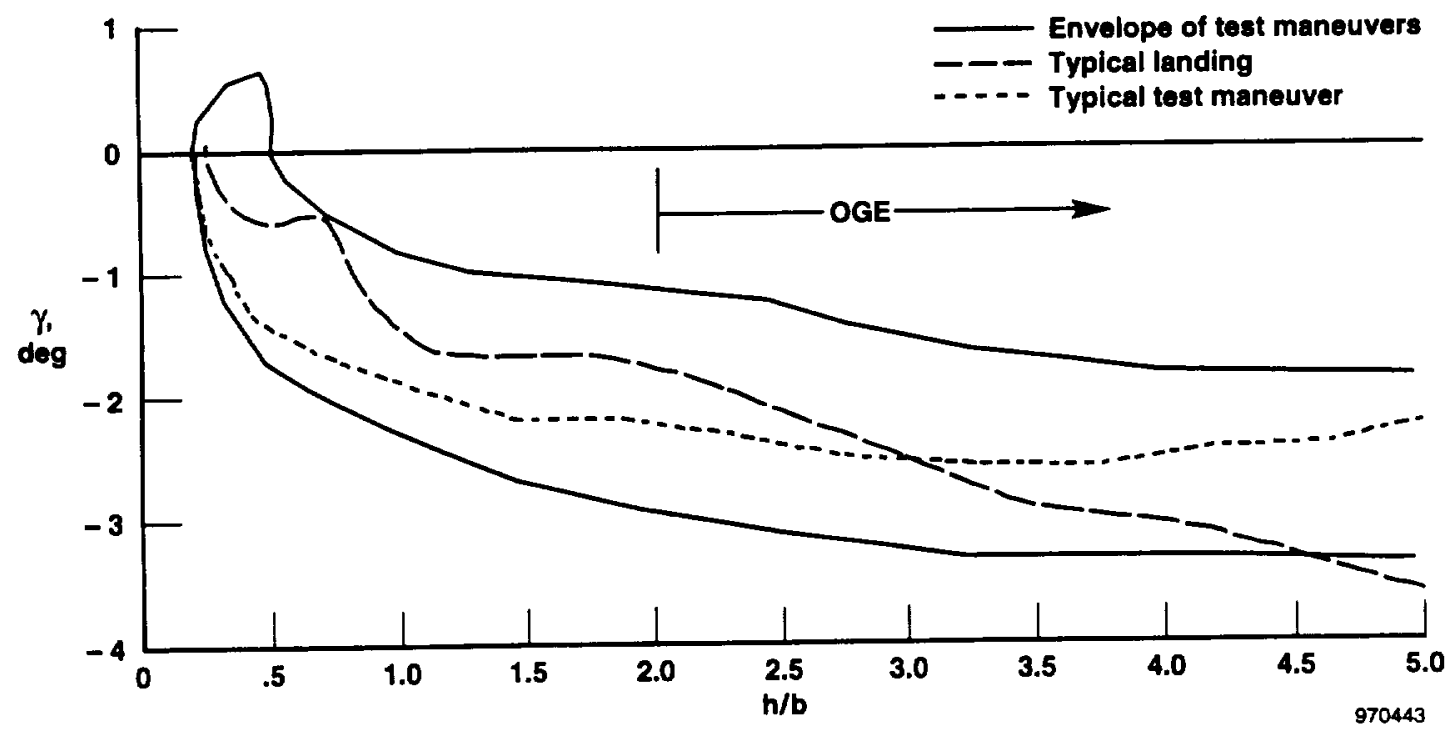

Figure 3. Flightpath angle variation during flight test maneuvers and a typical landing.

The time history for a typical F-16XL landing is also shown in figure 3 . Unlike the test maneuvers, the flightpath angle for typical landings tends to vary continuously during final approach. However, the range of flightpath angles encountered during typical landings is generally within the envelope of maneuvers conducted for this ground effect study.

The initial angle of attack for all maneuvers ranged from $11^{\circ}$ to $13^{\circ}$. No maneuvers were conducted if winds exceeded $5 \mathrm{kn}$ in any direction.

\section{Elight Data Analysis}

The overall approach to the analysis of the flight data was to first determine the forces and moments acting on the airplane during the stabilized descent prior to entering ground effect. These forces and moments were then subtracted from the total forces and moments acting on the airplane as it descended into ground effect and the differences attributed to the effect of ground proximity. The procedures were implemented using a series of FORTRAN computer programs which will now be described in greater detail.

Both the DGPS and PCM data streams included timeof-day information. The DGPS data (recorded at 1-sps) was linearly interpolated to provide a synchronous stream of data at the higher sample rate of the telemetered data (50-sps), and the two data sets were merged. As described earlier, the DGPS data were combined with the onboard measurement of pitch attitude to determine height of the wing aerodynamic center above ground.

For each maneuver, the engine rotational speeds were monitored to determine the time from which thrust could be assumed to be constant. The time segment from this point until the airplane descended to a wing altitude of two spans above the ground was then referred to as the out-of-ground effect (OGE) portion of the maneuver. The control surface positions and angles of attack were averaged during this time segment. An estimate of total airplane lift and drag coefficients was obtained from free-flight aerodynamic data based on the averaged OGE angle-of-attack and control surface positions. Assuming that the airplane was in a steady-state descent, these aerodynamic coefficients were used to estimate net engine thrust as follows:

$$
T=\left[C_{D_{\mathrm{OGE}}} \cos (\alpha)-C_{L_{\mathrm{OGE}}} \sin (\alpha)\right] S \bar{q}+W \sin (\theta)(1)
$$

For each maneuver, this value of thrust was assumed to be constant in subsequent calculations. Because the ground effect analysis will be determined primarily as the difference between OGE and in ground effect conditions, and because thrust is constant during the maneuvers, small errors in this thrust estimate will have little effect on the resulting ground effect increments.

The aerodynamic force coefficients on the airplane were then determined throughout the maneuver using 
the following equations, an example of the calculation for lift coefficient is shown in figure 4(a):

$$
\begin{gathered}
C_{X}=\frac{W a_{X}-T}{S \bar{q}} \\
C_{Z}=\frac{W a_{Z}}{S \bar{q}} \\
C_{L}=-C_{Z} \cos (\alpha)+C_{X} \sin (\alpha) \\
C_{D}=-C_{X} \cos (\alpha)-C_{Z} \sin (\alpha)
\end{gathered}
$$

Angular rates were always small and were therefore omitted from the analysis. Accelerations were measured directly, and free-stream dynamic pressure was determined from noseboom measurements. Airplane weight and inertias were estimated for each maneuver based on fuel tank quantities and recent ground measurements of the airplane.
The lift and drag coefficients were then averaged during the out-of-ground-effect portion of the maneuvers. These averages were subtracted from the total coefficients to yield the incremental changes that occurred in each axis during the maneuvers.

$$
\begin{aligned}
& \Delta C_{L_{\text {ge, uncorrecied }}}=C_{L}-C_{L_{\mathrm{OGE}}} \\
& \Delta C_{D_{\text {ge, uncorrected }}}=C_{D}-C_{D_{\mathrm{OGE}}}
\end{aligned}
$$

Example data for the incremental change in lift coefficient is shown in figure 4(b). The average value of the lift coefficient in the OGE portion of the maneuver is centered at a value of zero, as would be expected.

Variations in elevon position and angle of attack occurred during each maneuver and tended to increase as the airplane flew through ground effect. The effect of these variations had to be eliminated to determine the direct influence of ground effect. These trim changes

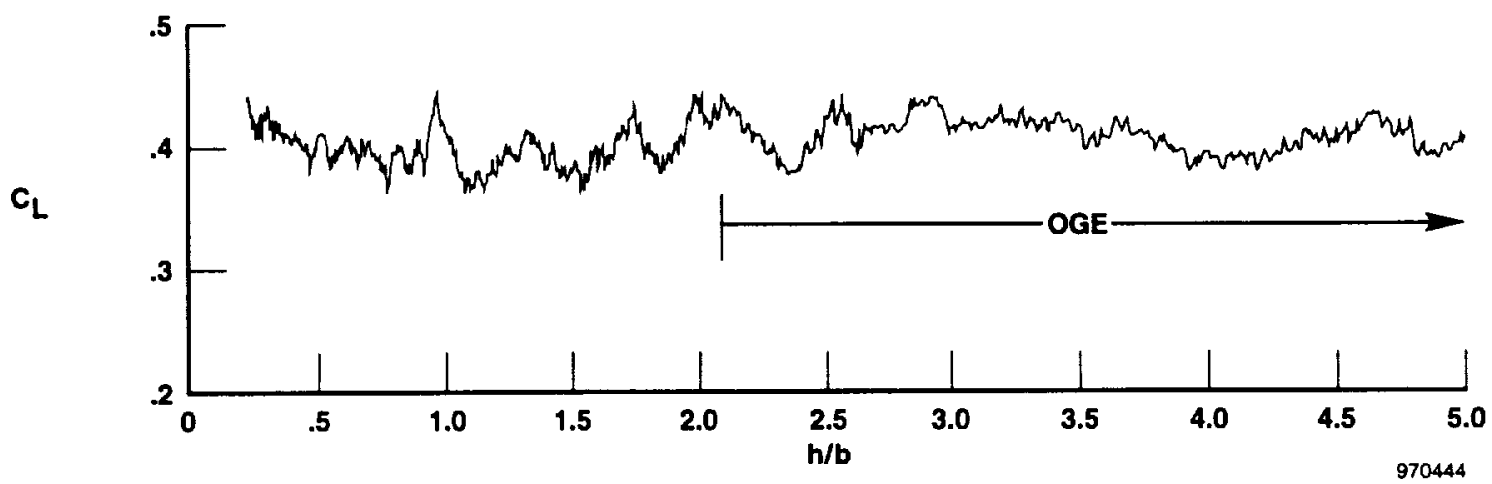

(a) Total lift coefficient.

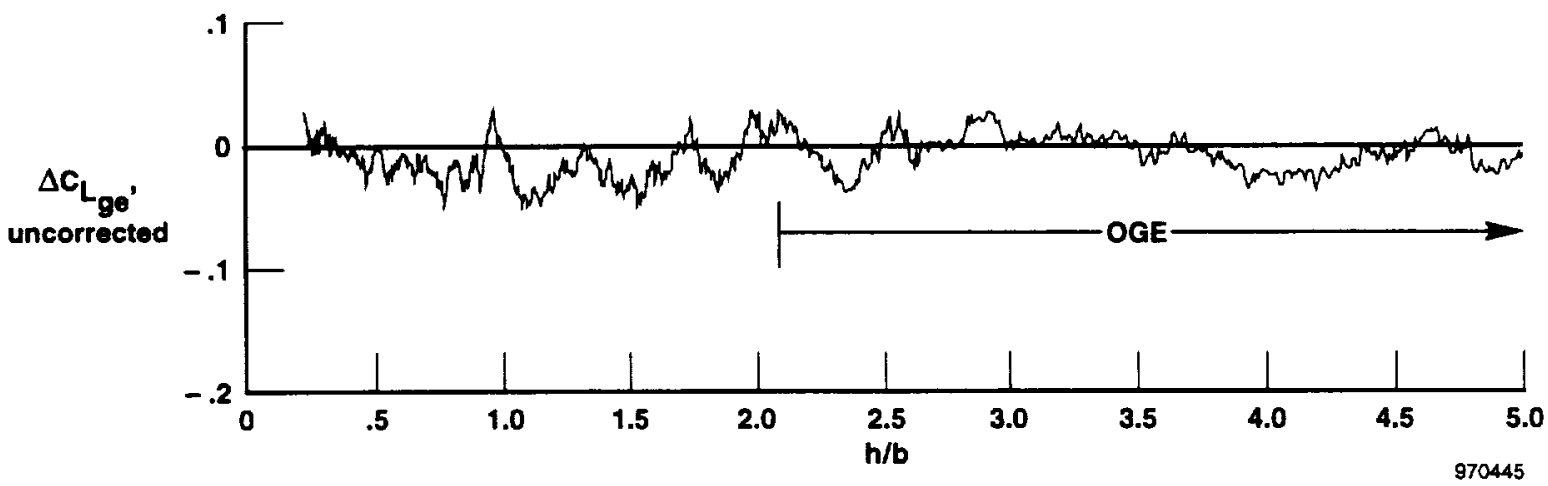

(b) Incremental change in lift coefficient caused by ground effect, uncorrected for $\delta e$ and $\alpha$ variation.

Figure 4. Computation of incremental change in lift coefficient due to ground effect. 
also serve as an indication of ground effect on the incremental change in pitching moment caused by ground effect, $\Delta C_{m_{g e}}$. The average values of elevon and angle of attack during the OGE portion of each maneuver were used as a reference from which the deviations could be measured. Aerodynamic derivatives obtained from previous flight testing were then used to extract the effects of trim changes during the maneuvers as follows:

$$
\begin{aligned}
\Delta C_{L_{g e}}= & \Delta C_{L_{g e, \text { uncorrected }}} \\
& -C_{L_{\alpha}}\left(\alpha-\alpha_{\mathrm{OGE}}\right)-C_{L_{\delta e}}\left(\delta e-\delta e_{\mathrm{OGE}}\right) \\
\Delta C_{m_{g e}}= & \Delta C_{m_{g e, \text { uncorrecied }}} \\
& -C_{m_{\alpha}}\left(\alpha-\alpha_{\mathrm{OGE}}\right)-C_{m_{\delta e}}\left(\delta e-\delta e_{\mathrm{OGE}}\right)
\end{aligned}
$$

A table look-up function was used to correct the drag coefficient data.

$$
\begin{aligned}
\Delta C_{D_{g e}}= & \Delta C_{D_{g e, \text { uncorrected }}} \\
& -\left[C_{D}(\alpha, \delta e)-C_{D}\left(\alpha_{\mathrm{OGE}}, \delta e_{\mathrm{OGE}}\right)\right]
\end{aligned}
$$

Again, an example of the lift coefficient calculation is shown in figure $4(\mathrm{c})$. The elimination of oscillations and deviations in the data trend (particularly in the OGE portion of the maneuver) indicates that the corrections made for trim changes during the maneuver have been effective.

A limitation of this analysis approach is that it assumes that the control surface and angle-of-attack derivatives are not functions of ground effect. This simplification is not expected to significantly effect the results because the excursions in $\delta$ e and particularly $\alpha$ were quite small for all maneuvers (generally less than $3^{\circ}$ for $\delta e$ and less than $1^{\circ}$ for $\alpha$ ).

\section{Development of Dynamic Ground Effect Engineering Model}

The dynamic ground effect problem may be approached through the use of unsteady computational fluid dynamic methods or experimental facilities with the ability to dynamically vary model position. These methods are time consuming and expensive and may still not provide a basis for developing trends due to dynamic effects. A more generic engineering solution for the problem is desirable to support simulation or other flight mechanics analysis tools.

The primary characteristics of steady-state ground effect can be predicted using linear aerodynamic theory and the principal of super-positioning. ${ }^{1}$ The ground plane is typically simulated by including a mirror image of the airplane in the flow field (fig 5). The resulting plane of symmetry provides the effective ground plane. This method can be applied to simple lifting line theory, vortex lattice models, or panel methods to analyze complex configurations.

Note that in figure 5 the downwash field of the real and imaginary airplanes converge, and based on the discussion of reference 1, much of the effect of ground proximity results from the effect of this imaged wake on the real airplane. The resulting steady-state ground effect on the lift coefficient can be linearly related to the freestream lift coefficient.

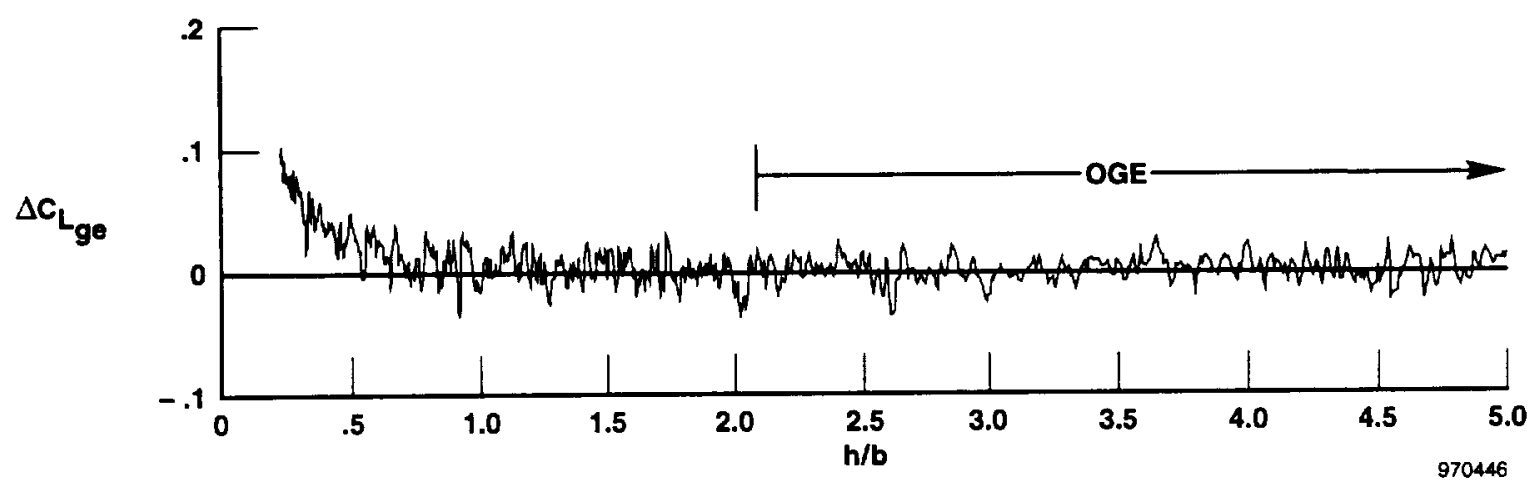

(c) Corrected ground effect increment.

Figure 4. Concluded. 


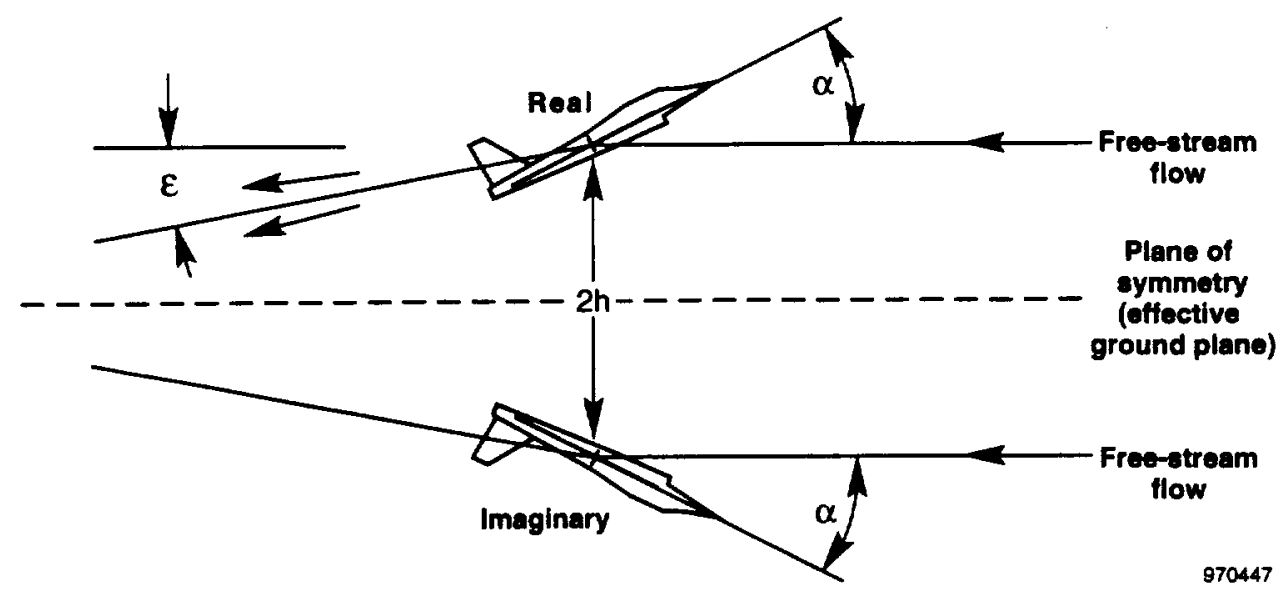

Figure 5. Analytical modeling of steady-state ground effect.

$$
k_{1}=\frac{\Delta C_{L_{g e, s t e a d y-s t a t e}}}{C_{L_{\mathrm{OGE}}}}
$$

The downwash field for an airplane may be complex, but linear aerodynamic theory implies that an effective downwash angle $(\varepsilon)$ for the complete airplane can be defined and that it is a direct function of lift coefficient as follows:

$$
k_{2}=\frac{C_{L_{\mathrm{OGE}}}}{\varepsilon}
$$

It is hypothesized that this super-position model can be modified, as shown in figure 6 , to simulate the key aspects of the dynamic ground effect situation. The ground plane is tilted at an angle of $\gamma$ relative to the flightpath of the real airplane. The effective downwash angle of the imaged airplane is reduced by an angle of $2 \gamma$, so that the two wakes converge symmetrically toward the tilted ground plane (eq. 13).

$$
\varepsilon_{\text {image }}=\varepsilon+2 \gamma
$$

where $\gamma$ is negative for descending flight.

In the theoretical model, the imaged downwash angle can be reduced by reducing the lift coefficient of the imaginary airplane as follows:

$$
C_{L_{\text {OGE, image }}}=k_{2}(\varepsilon+2 \gamma)
$$

Based on characteristics of linear aerodynamic theory, it is further hypothesized that the constant of

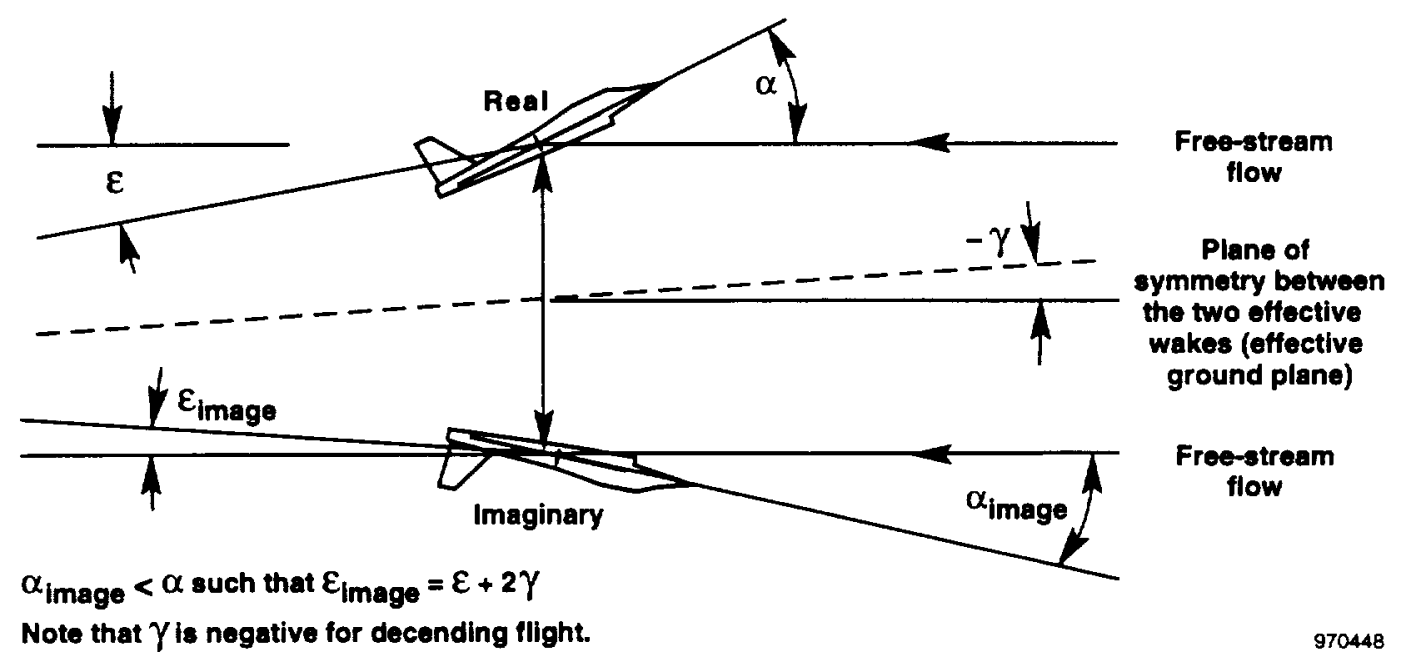

Figure 6. Proposed engineering model of dynamic ground effect. 
proportionality defined in equation 11 also applies to the dynamic situation if $C_{L_{\mathrm{OGE} \text {, image }}}$ is substituted for the value of $C_{L_{\mathrm{OGE}}}$ used in the steady-state data as follows:

$$
\Delta C_{L_{\text {ge, dynamic }}}=k_{1} C_{L_{\mathrm{OGE} \text {, image }}}
$$

Substituting from equations 11 and 14 and rearranging terms gives equation 16.

$$
\Delta C_{L_{\text {ge, dynamic }}}=\frac{\Delta C_{L_{\text {ge, steady-state }}}}{C_{L_{\mathrm{OGE}}}} k_{2}(\varepsilon+2 \gamma)
$$

This implies that the ground effect increment in descending flight is the same as the steady-state ground effect increment for the same configuration measured at a reduced free-stream lift coefficient.

Although the effective downwash angle for a given airplane may be difficult to predict, a simple computation for elliptically loaded wings is provided in reference 18 .

$$
\varepsilon=\frac{C_{L} S}{\pi b^{2}}
$$

Considering the approximate nature of this engineering model, it is assumed that the effects of nonelliptic loading would not induce significant errors for most airplanes. (The use of the planform efficiency factor may be explored as a method to account for nonelliptical loading.) The equation for effective downwash angle for elliptically loaded wings and equation 12 are substituted into equation 16 , which can be rearranged to give:

$$
\frac{\Delta C_{L_{\text {ge, dynamic }}}}{\Delta C_{L_{\text {ge, seady-state }}}}=1+\frac{b^{2} \pi}{C_{L_{O G E} S}} 2 \gamma
$$

This provides a simple method to estimate dynamic ground effect based on the flightpath angle and the steady-state ground effect data. Because ground effects on induced drag coefficient and pitching moment have been simulated using the same principles of superposition aerodynamic modeling, it is assumed that the same approach could be used to predict dynamic effects on these terms. This concept is encouraging because it would allow the use of conventional steady-state ground effect prediction tools and a simple algebraic formula to predict characteristics for any dynamic condition.

\section{$\underline{\text { Results and Discussion }}$}

Force and moment coefficient increments, normalized to OGE lift coefficient from an example maneuver are shown in figure 7. All maneuvers yielded the same general trends and magnitudes. Ground effect increased lift by over 20 percent at ground level $(h / b=0.2)$. The normalized drag coefficient increment at ground level

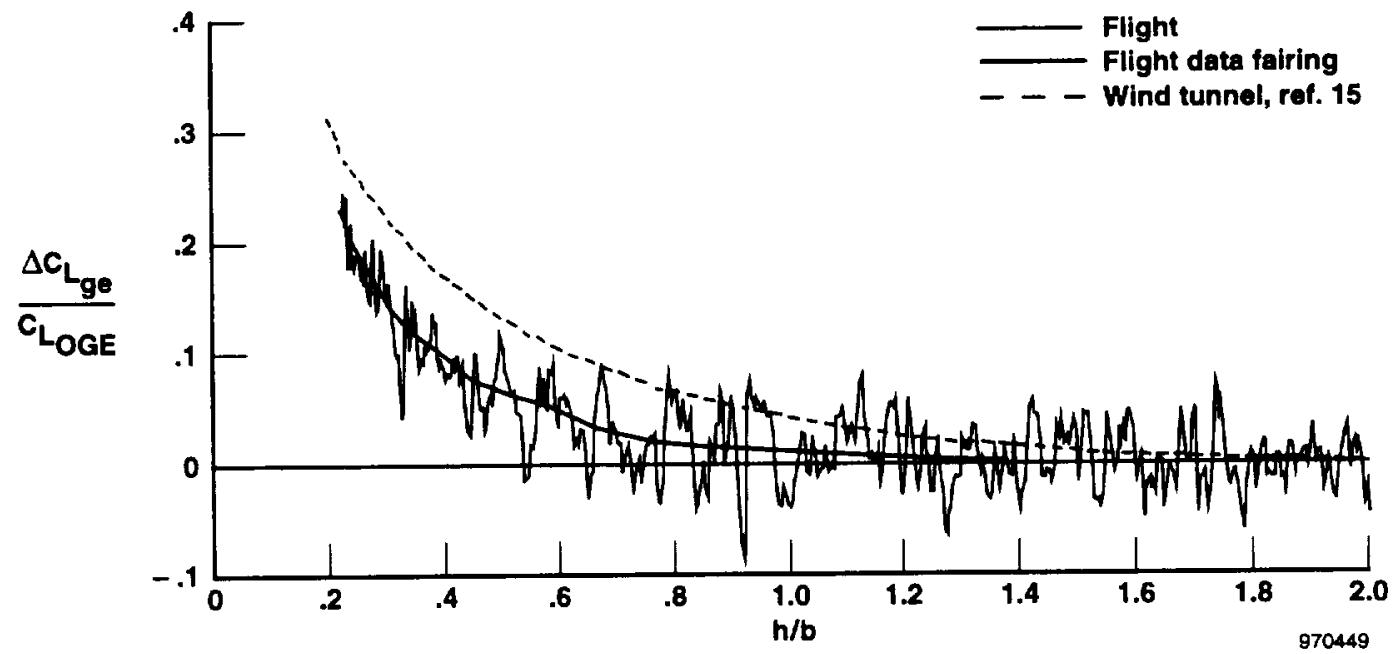

(a) Lift.

Figure 7. Force and moment coefficient increments due to ground effect, normalized to OGE lift coefficient, flight and wind-tunnel data.

11

American Institute of Aeronautics and Astronautics 


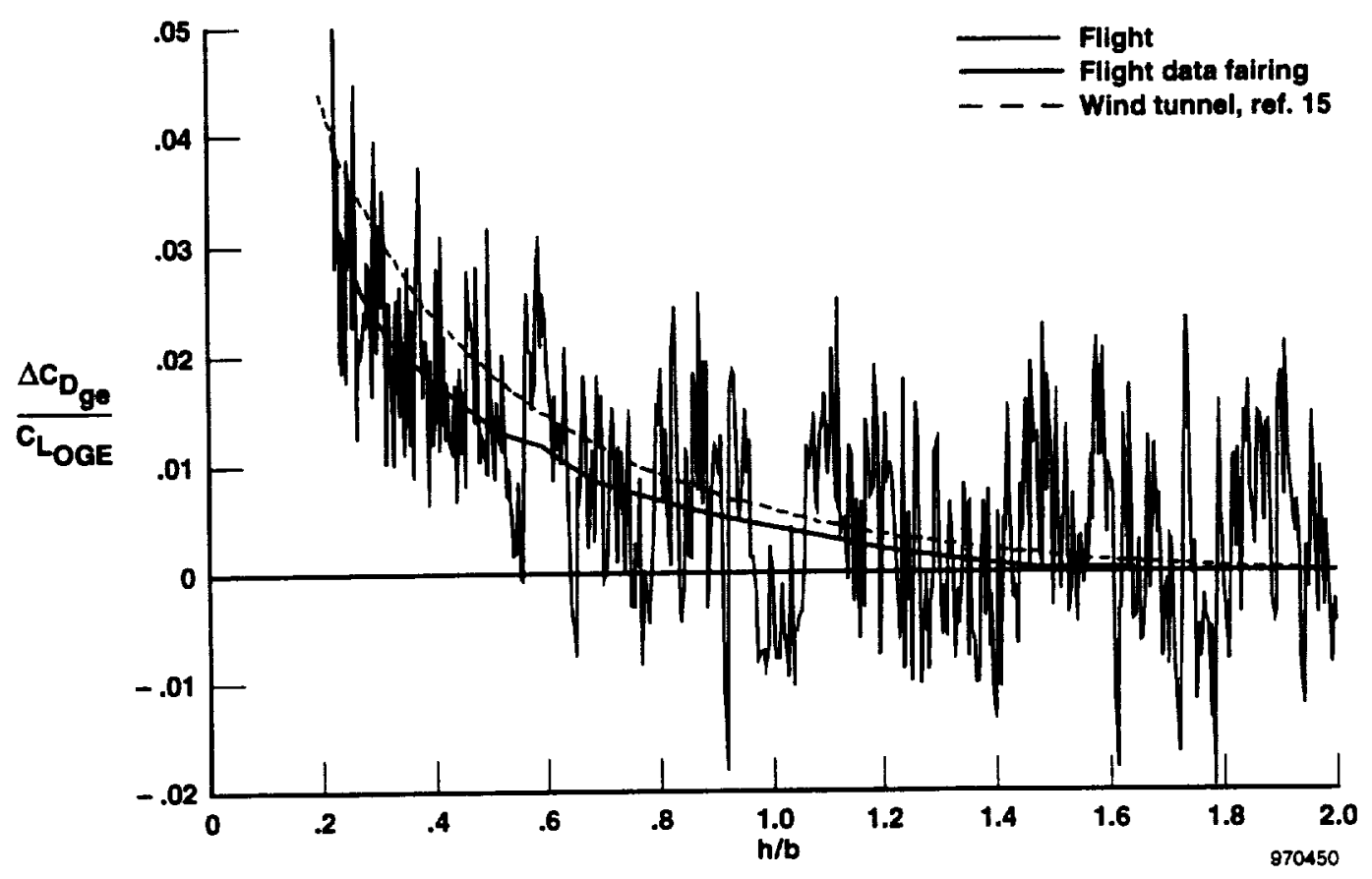

(b) Drag.

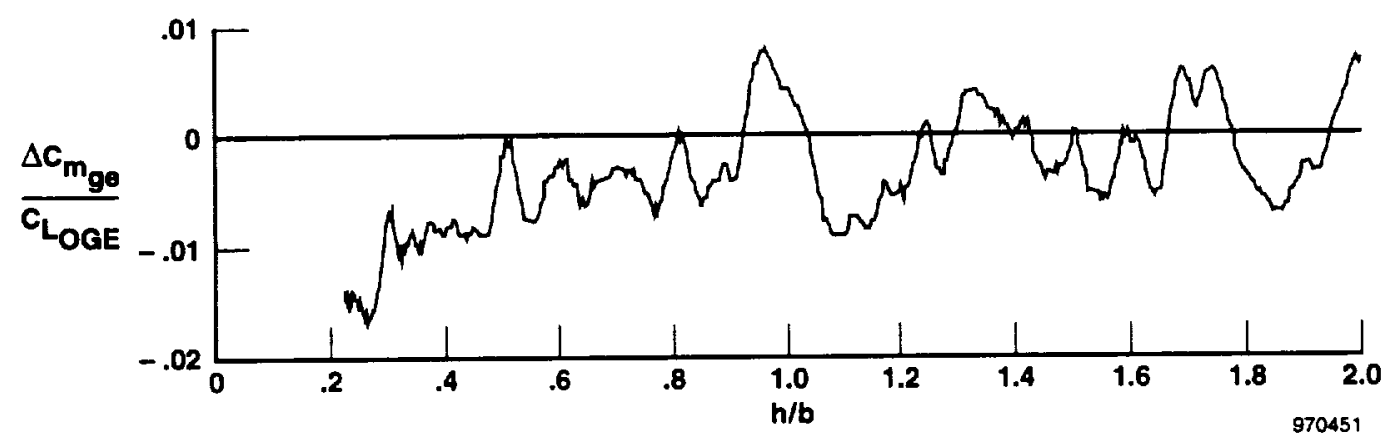

(c) Pitching moment.

Figure 7. Concluded.

was also positive but relatively smaller, $\Delta C_{D_{e}}$ ' $C_{L_{\mathrm{OGE}}}=0.03$. In pitch, the data consistently indicated a nosedown moment increment. The noise in the flight data is caused by the noise in the accelerometer and angle-of-attack vane measurements. Because the lift increment is larger than the drag increment, the signalto-noise ratio in this axis is significantly improved.

F-16XL wind-tunnel data for the lift and drag increments ${ }^{15}$ are also shown in figure 7. In both cases, the flight maneuver results are significantly lower than the wind-tunnel data which were obtained under steadystate conditions. This fundamental difference is consistent with data from other configurations for which steady-state and dynamic lift data are available (fig. 8). As shown, both the steady and dynamic F-16XI data sets fit reasonably well into the overall levels of ground effect when considered as a function of aspect ratio.

A subset of the best maneuvers was selected for further analysis. Maneuvers which included abrupt control inputs or in which the OGE data were not smooth and consistent were eliminated. The lift data for these 


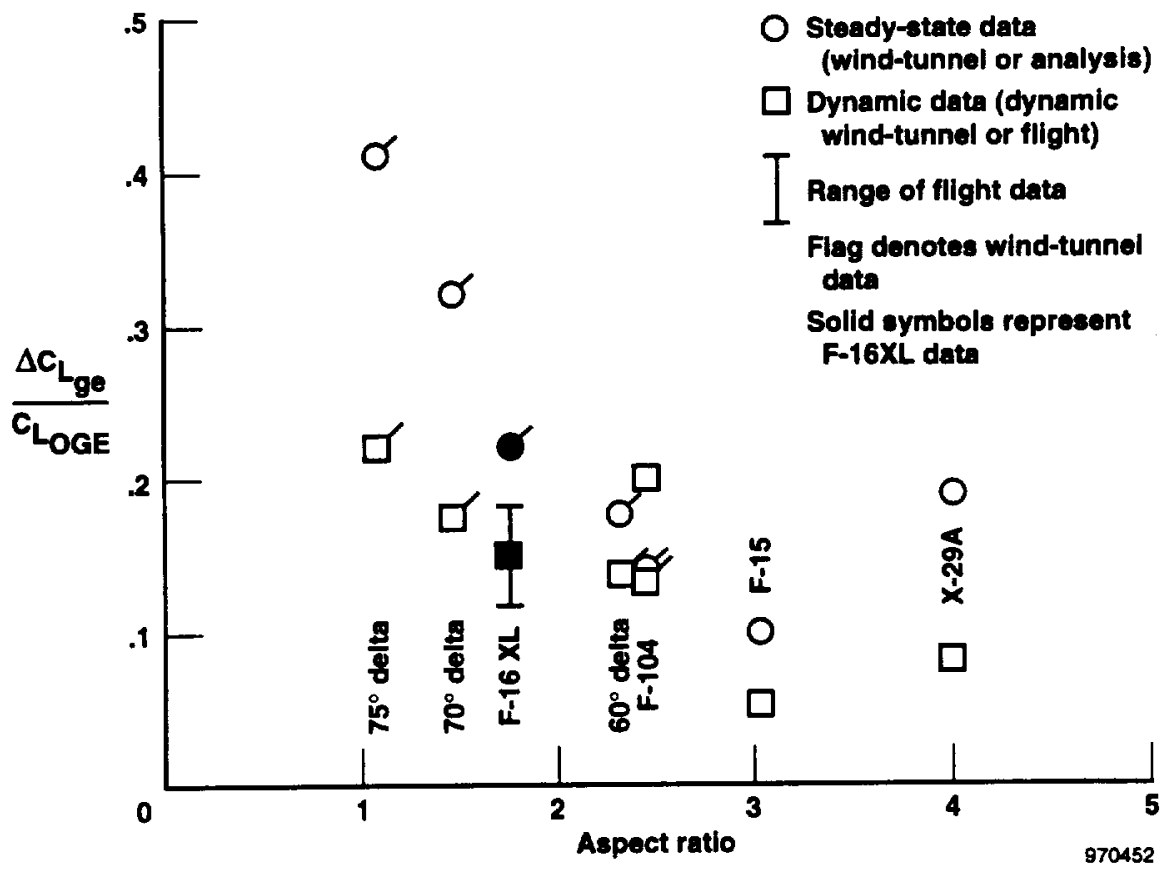

Figure 8. Comparison of steady-state and dynamic ground effects for various configurations, all data at $h / b=0.3$. (Data from references $2,5,10,11$, and current study.)

maneuvers were faired by hand (fig. 9) and then correlated with trends in flightpath angle (fig. 10). The steady-state wind-tunnel value is also shown on figure 10 at $\gamma=0$. At heights between 0.3 and 0.4 span, the flight data indicate a poorly defined positive slope.

When examining the flight data at this level of detail, it is important to remember the measurement noise seen in the typical data of figure 7 . At low altitudes where the value of $\Delta C_{L_{g e}} / C_{L_{\mathrm{OGE}}}$ varies rapidly, the DGPS height measurement errors of $\pm 1 \mathrm{ft}$ and the low DGPS sample rate can also be significant, particularly when comparing results from different maneuvers.

For the flight maneuvers shown in figure 10, the average value of $C_{L_{\mathrm{OGE}}}$ was 0.411 . Using this value and the steady-state wind-tunnel data, predictions based on

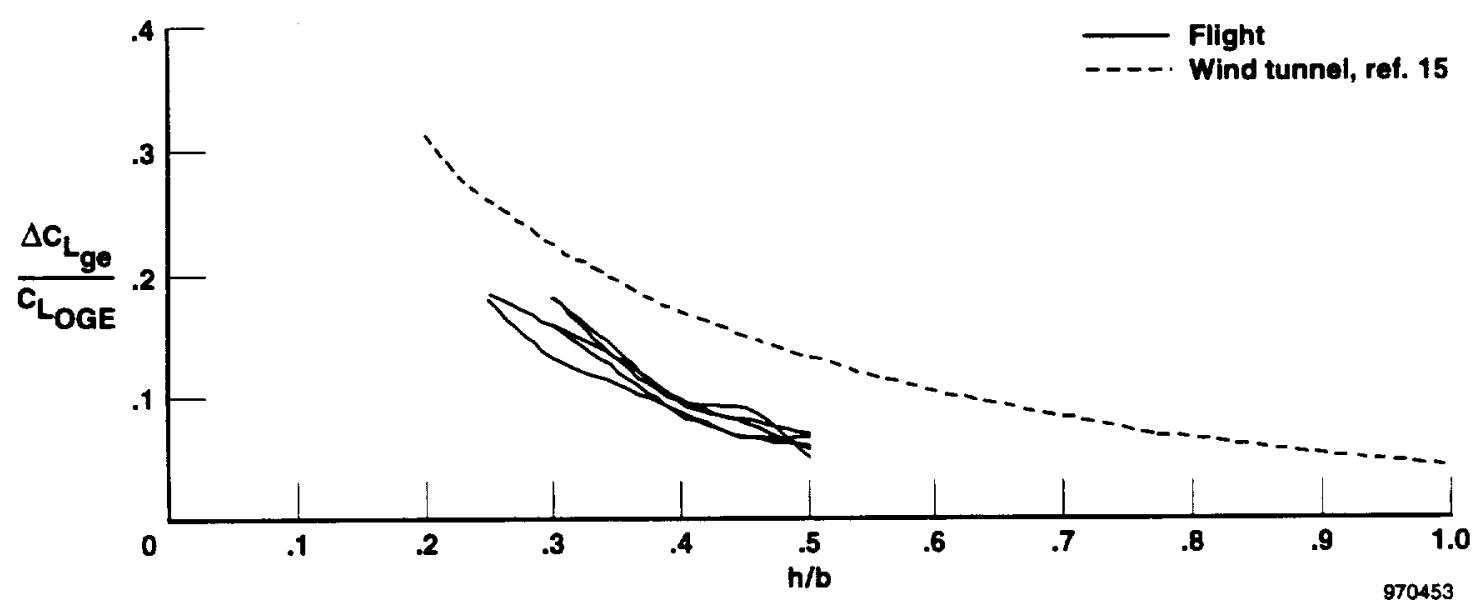

Figure 9. Summary of lift coefficient data for several maneuvers. 


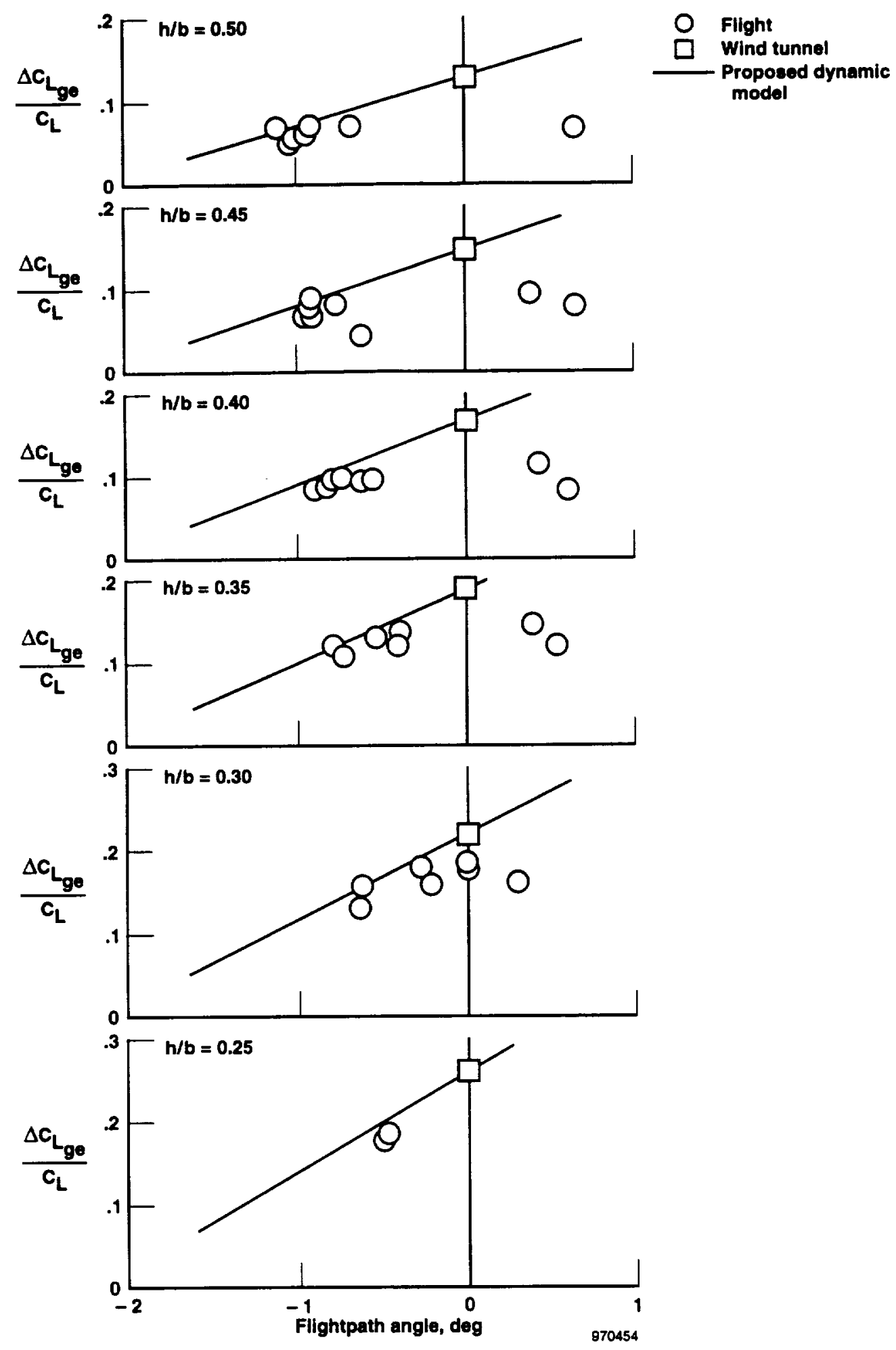

Figure 10. Normalized increase in lift and coefficient due to ground effect shown as a function of flightpath angle. 
the dynamic ground effect algorithm proposed in equation 18 are also shown. The slope of this line accurately predicts the overall difference between the flight and wind-tunnel data sets for descending flight.

A limited amount of data was obtained at positive flightpath angles. These points were obtained when the airplane naturally flared during a maneuver caused by the additional lift from ground effect and then began to ascend. The proposed engineering model implies that the ground effect increment should always increase with increasing flightpath angle. However as seen in figure 10 , the data at positive $\gamma$ does not follow that trend. Because of the minimal data available, it is unclear whether this indicates a problem in the flight measurement, a flaw in the engineering model, or possibly the effect of lag.

The engineering method proposed in this paper assumes that the dynamic effect is a function of the instantaneous flightpath angle. This assumption can be questioned because the location of the wake of an airplane is a function of its overall flightpath trajectory, not just the instantaneous flight conditions. In other words, it is likely that dynamic effects on $\Delta C_{L_{g e}}$ may lag the current value of flightpath angle. If lag is a significant element of the problem, then the detailed dynamic aspects of ground effect will be especially difficult to predict for normal aircraft landings in which flightpath angle varies continuously.

To further test the proposed dynamic ground effect algorithm, the proposed engineering method was also applied to data obtained for an F-15 airplane. ${ }^{11}$ These F-15 data were selected because maneuvers were intentionally performed at a variety of flightpath angles. Test data were obtained at two different approach speeds (one with flaps up and the other for flaps down). The OGE lift coefficient was estimated using the average weight of the airplane and the approach speed. Figure 11 shows the resulting data as a function of flightpath angle. A steady-state analytical prediction is also shown (ref. 11). The proposed dynamic algorithm was then applied using the steady-state ground effect increment and estimated $C_{L_{\mathrm{OGE}}}$. Again, the proposed method generally predicts the relationship between the dynamic flight and steady-state data sets. One difference between the F-15 maneuvers and F-16XI testing was that the flightpath angle of the F-15 airplane was held constant throughout the maneuver. During the F-16XI testing flightpath angle was allowed to vary. The F-15 data set should be less susceptible to any effects of lag.

Evaluating the proposed engineering model of dynamic ground effect for a significantly different configuration would be highly desirable; particularly an airplane with larger aspect ratio or with different landing approach $C_{L}$. Unfortunately, data from other configurations in figure 8 were not published with corresponding flightpath angle data.

\section{Concluding Remarks}

Flight-determined ground effect characteristics for an F-16XI airplane have been presented and correlated with wind-tunnel predictions and similar results from other aircraft. Comparisons of flight data from several maneuvers provided consistent data, positive increments in lift and drag coefficients, and a nosedown pitching moment coefficient increment.

The same flight test technique had been used in previous studies, except that space positioning information was obtained from the differential global positioning system (DGPS) in this experiment. The accuracy of the DGPS was equivalent to optical tracking methods which have been used in the past, but it was found to be operationally more attractive.

The dynamic flight-determined lift and drag coefficient increments were measurably lower than steady-state wind-tunnel predictions. This relationship is consistent with the results of other aircraft for which similar data are available.

In a closer examination of the flight data, a poorly defined correlation of the lift coefficient increment caused by ground effect with instantaneous flightpath angle was seen at some altitudes. The measurement uncertainty at this level of detailed analysis, however, is large because of noise in the basic acceleration, angleof-attack measurements, and DGPS accuracy. It is also possible that the lift coefficient increment is not a simple function of instantaneous flightpath angle but is more sensitive to the history of the trajectory. 

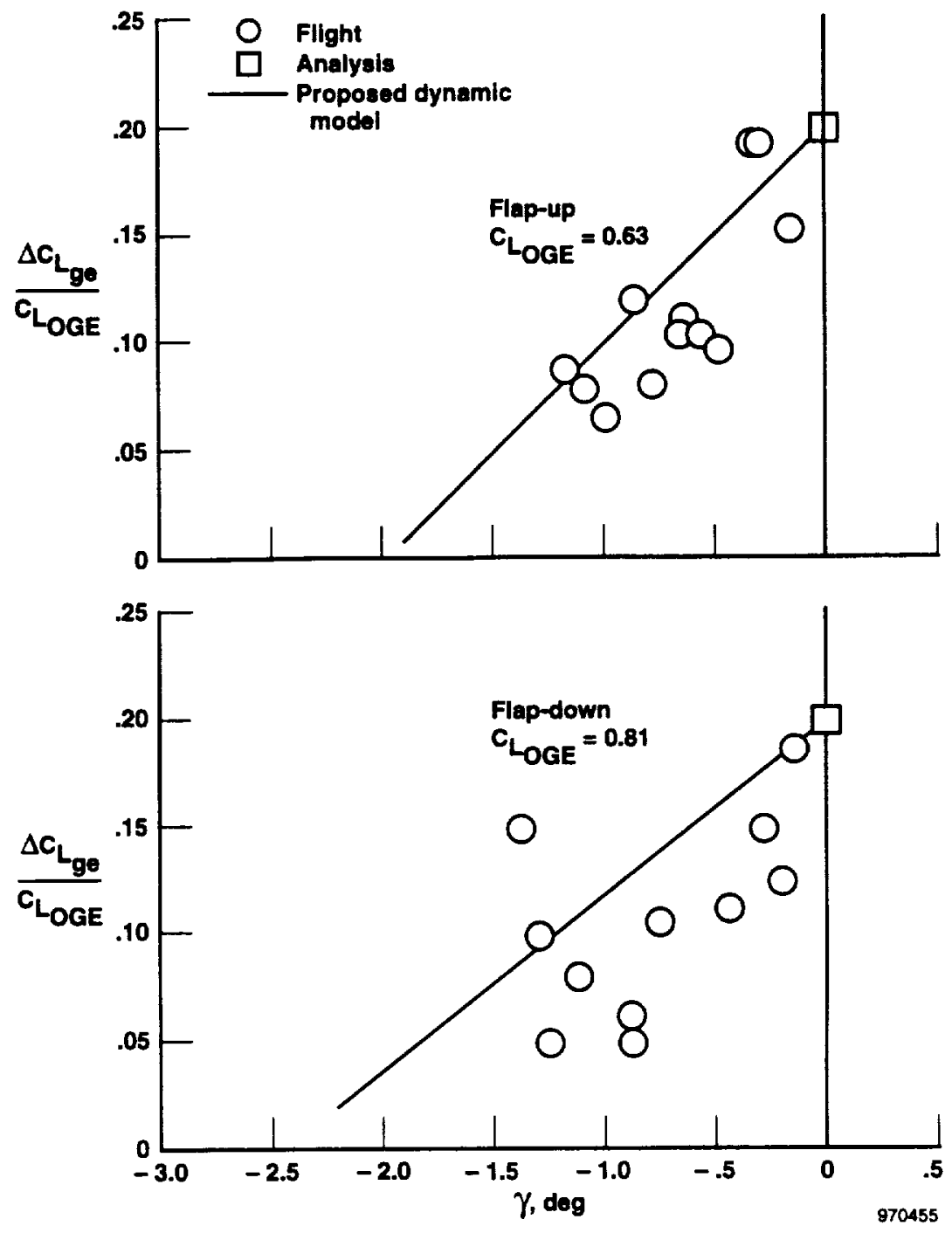

Figure 11. Normalized lift coefficient increment for an F-15 airplane. $h / b=0.3$.

An engineering model of dynamic ground effect was developed based on linear aerodynamic theory and the principal of super-positioning of flows. This model was applied to the F-16XL data set and to previously published data for an F-15 airplane. In both cases, the model provided an effective estimate of the ratio between the steady-state and dynamic data sets. Obtaining similar data for other configurations would be desirable, particularly an aircraft with larger aspect ratio or different approach speed.

\section{References}

${ }^{1}$ McDonnell Douglas Corporation, USAF Stability and Control DATCOM, U.S. Air Force Flight Dynamics
Laboratory, Wright-Patterson AFB, Ohio, Oct. 1960 (revised Apr. 1976).

${ }^{2}$ Baker, Paul A., Schweikhard, William G., and Young, William R., Flight Evaluation of Ground Effect on Several Low-Aspect Ratio Airplanes, NASA TN-D-6053, Oct. 1970.

${ }^{3}$ Lee, Pai-Hung, Lan, C. Edward, and Muirhead, Vincent U., An Experimental Investigation of Dynamic Ground Effect, NASA CR-4105, 1987.

${ }^{4}$ Chang, Ray Chung and Muirhead, Vincent U., "Effect of Sink Rate on Ground Effect of Low-AspectRatio Wings," J. of Aircrafi, vol. 24, no. 3, Mar. 1986, pp. 176-180. 
${ }^{5}$ Chang, Ray Chung, "An Experimental Investigation of Dynamic Ground Effect," University of Kansas PhD Dissertation, 1985.

${ }^{6}$ Kemmerly, Guy T. and Paulson, J.W., Jr., Investigation of Moving-Model Technique for Measuring Ground Effects, NASA TM-4080, 1989.

${ }^{7}$ Kemmerly, Guy T., Dynamic Ground-Effect Measurements on the F-15 STOL and Maneuver Technology Demonstrator (S/MTD) Configuration, NASA TP-3000, 1990.

${ }^{8}$ Paulson, John W., Jr., Kemmerly, Guy T., and Gilbert, William P., "Dynamic Ground Effects," Aerodynamics of Combat Aircraft Controls and of Ground Effects, AGARD CP-465, 1990, pp. 21-1-21-12.

${ }^{9}$ Kemmerly, G.T., Paulson, J.W., Jr., and Compton, M., "Exploratory Evaluation of Moving-Model Technique for Measurement of Dynamic Ground Effects," $J$. of Aircraft, vol. 25, no. 6, June 1988, pp. 557-562.

${ }^{10}$ Curry, Robert E., Moulton, Bryan J., and Kresse, John, An In-Flight Investigation of Ground Effect on a Forward-Swept Wing Airplane, NASA TM-101708, Sept. 1989. (Also presented at the AGARD Fluid Dynamics Panel Symposium on "Aerodynamics of Combat Aircraft Controls and of Ground Effects," Oct. 2-5, 1989, Madrid, Spain.)

${ }^{11}$ Corda, Stephen, Stephenson, Mark T., Burcham, Frank W., and Curry, Robert E., Dynamic Ground Effects
Flight Test of an F-15 Aircrafi, NASA TM-4604, Sept. 1994.

${ }^{12}$ Snyder, C. Thomas, Drinkwater III, Fred J., and Jones, A. David, A Piloted Simulator Investigation of Ground Effect on the Landing Maneuver of a Large, Tailless, Delta-Wing Airplane, NASA TN-D-6046, Oct. 1970.

${ }^{13}$ Boeing Commercial Airplanes, New Airplane Development, High-Speed Civil Transport Study, NASA CR-4233, 1989.

${ }^{14}$ Hillaker, H.J., F-16XL Flight Test Program Overview, AIAA-83-2730, Nov. 1, 1983.

${ }^{15}$ General Dynamics, Fort Worth Division, F-16XL Final Performance Flight Test Results (PHASE I), 400PR141, July 31, 1985, Contract F33657-78G-004009.

${ }^{16}$ Ashtech $^{\mathrm{TM}}$ Precise Differential GPS Navigation (PNAV) Trajectory Software User's Guide, Software Version 2.1.00-T, doc. no. 600200, rev. B, May 1994.

${ }^{17}$ Schweikhard, William, "A Method for In-Flight Measurement of Ground Effect on Fixed-Wing Aircraft," J. of Aircraft, vol. 4, no. 2, Mar-Apr. 1967, pp.101-104.

${ }^{18}$ Anderson, John D., Jr., Fundamentals of Aerodynamics, McGraw-Hill Book Company, New York, New York, 1984. 
Pubic reporting burden for this collection of intormation is estimated to awerage 1 hour per response, including the thme for reviewing instructions, searching existing date sources. gathering and Pan manting VA $22202-430$, and to the Otfice of Management and Budoet. Papenwork Reduction Propect (0704-0188), Washington, DC 20503.

\begin{tabular}{|l|l|l}
\hline 1. ACENCY USE ONLY (Leave blank) & $\begin{array}{c}\text { 2 AEPORT DATE } \\
\text { August } 1997\end{array}$ & $\begin{array}{c}\text { 3. REPOFT TYPE AND DATES COVEAED } \\
\text { Technical Memorandum }\end{array}$
\end{tabular}

4.TILE AND SUETILE

5. FUNDING NUMBERS

Dynamic Ground Effect for a Cranked Arrow Wing Airplane

6. AMTHOR(S)

529-31-24-00-24-00-RPT

Robert E. Curry

7. PERFORMING ORGANRATION NAME(8) AND ADDRESS(ES)

8. PERFORMING ORGAMIZATION

REPOAT NUMBER

NASA Dryden Flight Research Center

P.O. Box 273

H-2177

Edwards, California 93523-0273

10. SPONSORINGMONTTORING

AOENCY REPORT NUMBEA

National Aeronautics and Space Administration

Washington, DC 20546-0001

NASA TM-4799

\section{SUPPLEMENTAFY NOTES}

Presented at AIAA Atmospheric Flight Mechanics Conference, New Orleans, Louisiana, August 11-13, 1997 as AIAA-97-3649.

12.. DISTRIBUTIONAVAILABILTY STATEMENT

12b. DISTRIQUTKON CODE

Unclassified-Unlimited

Subject Category 02

\section{ABSTRACT (Maximum 200 words)}

Flight-determined ground effect characteristics for an F-16XL airplane are presented and correlated with wind tunnel predictions and similar flight results from other aircraft. Maneuvers were conducted at a variety of flightpath angles. Conventional ground effect flight test methods were used, with the exception that space positioning data were obtained using the differential global positioning system (DGPS). Accuracy of the DGPS was similar to that of optical tracking methods, but it was operationally more attractive. The dynamic flightdetermined lift and drag coefficient increments were measurably lower than steady-state wind-tunnel predictions. This relationship is consistent with the results of other aircraft for which similar data are available. Trends in the flight measured lift increments caused by ground effect as a function of flightpath angle were evident but weakly correlated. An engineering model of dynamic ground effect was developed based on linear aerodynamic theory and super-positioning of flows. This model was applied to the F-16XI data set and to previously published data for an F-15 airplane. In both cases, the model provided an engineering estimate of the ratio between the steady-state and dynamic data sets.

\begin{tabular}{|c|c|c|c|}
\hline \multirow{2}{*}{\multicolumn{3}{|c|}{$\begin{array}{l}\text { 14. SUBJECT TERMS } \\
\text { Aerodynamic ground effect, Cranked arrow wing, Dynamic ground effect, Flight } \\
\text { testing, Supersonic transport }\end{array}$}} & \multirow{2}{*}{\begin{tabular}{|l} 
15. NUMBER OF PAGES \\
21 \\
$\begin{array}{c}\text { 16. PAICE CODE } \\
\text { AO3 }\end{array}$ \\
\end{tabular}} \\
\hline & & & \\
\hline $\begin{array}{l}\text { 17. SECURTY CLASSIFICATION } \\
\text { OF REPORT }\end{array}$ & $\begin{array}{l}\text { 18. SECUATTY CLASSIFICATION } \\
\text { OF THIS PAGE }\end{array}$ & $\begin{array}{l}\text { 19. SECUATY CLASSIFICATION } \\
\text { OF ABSTRACT }\end{array}$ & 20. LIMITATION OF ABSTRACT \\
\hline Unclassified & Unclassified & Unclassified & Unlimited \\
\hline
\end{tabular}

